\title{
Diabetes and fractures
}

Citation for published version (APA):

Rasmussen, N. H., Dal, J., de Vries, F., van den Bergh, J. P., Jensen, M. H., \& Vestergaard, P. (2020). Diabetes and fractures: new evidence of atypical femoral fractures? Osteoporosis International, 31(3), 447-455. https://doi.org/10.1007/s00198-019-05224-y

Document status and date:

Published: 01/03/2020

DOI:

10.1007/s00198-019-05224-y

Document Version:

Publisher's PDF, also known as Version of record

Document license:
Taverne

Please check the document version of this publication:

- A submitted manuscript is the version of the article upon submission and before peer-review. There can be important differences between the submitted version and the official published version of record.

People interested in the research are advised to contact the author for the final version of the publication, or visit the DOI to the publisher's website.

- The final author version and the galley proof are versions of the publication after peer review.

- The final published version features the final layout of the paper including the volume, issue and page numbers.

Link to publication

\footnotetext{
General rights rights.

- You may freely distribute the URL identifying the publication in the public portal. please follow below link for the End User Agreement:

www.umlib.nl/taverne-license

Take down policy

If you believe that this document breaches copyright please contact us at:

repository@maastrichtuniversity.nl

providing details and we will investigate your claim.
}

Copyright and moral rights for the publications made accessible in the public portal are retained by the authors and/or other copyright owners and it is a condition of accessing publications that users recognise and abide by the legal requirements associated with these

- Users may download and print one copy of any publication from the public portal for the purpose of private study or research.

- You may not further distribute the material or use it for any profit-making activity or commercial gain

If the publication is distributed under the terms of Article $25 \mathrm{fa}$ of the Dutch Copyright Act, indicated by the "Taverne" license above, 


\title{
Diabetes and fractures: new evidence of atypical femoral fractures?
}

\author{
N.H. Rasmussen ${ }^{1}$ (ID • J. Dal ${ }^{2}$ • F. de Vries ${ }^{3,4} \cdot$ J.P. van den Bergh ${ }^{5,6,7} \cdot$ M.H. Jensen ${ }^{1}$ • P. Vestergaard ${ }^{1}$
}

Received: 20 July 2019 / Accepted: 5 November 2019 / Published online: 14 December 2019

(C) International Osteoporosis Foundation and National Osteoporosis Foundation 2019

\begin{abstract}
Summary Patients with diabetes have an increased risk of fractures. In this study, subtrochanteric and femoral shaft fractures were increased in patients with type 1 diabetes compared with the general population. In the light of this, more evidence points towards an association between diabetes and atypical femoral fractures.

Introduction Patients with diabetes have an increased risk of femoral fractures, but little is known about the risk of atypical femoral fractures (AFFs). The aim of this study was to identify the risk of subtrochanteric and femoral shaft (ST/FS) fractures and estimate the risk of AFFs in patients with type 1 (T1D) and type 2 diabetes (T2D).

Methods From the nationwide Danish National Patient Register, we identified patients with T1D $(n=19,896)$, T2D $(n=$ $312,188)$, and sex- and aged-matched controls without diabetes $(n=996,252)$ from the general population and all ST/FS fractures $(n=7509)$. Data were analyzed using a Cox proportional-hazards model and the incidence rate and rate ratio of ST/FS fractures were estimated.

Results The incidence rate of ST/FS fractures in T1D was 52.14 events per 100,000 person years and 73.21 per 100,000 person years in T2D. T1D was associated with an increased risk of ST/FS (HR 2.07 (95\% CI 1.68-2.56)), whereas T2D was not (HR 0.99 (95\% CI 0.94-1.10)). Previous ST/FS fractures were associated with an increased risk of subsequent ST/FS fractures (HR 6.95 (95\% CI 6.00-8.05)) and the use of bisphosphonates with an increased risk of ST/FS fractures (HR 1.72 (95\% CI 1.54 $1.91)$ ).

Conclusion Patients with T1D have a higher risk of ST/FS fractures compared with sex- and age-matched controls. Since a proportion of ST/FS fractures are classified as AFFs, this could point towards the fact that AFFs also are increased in patients with T1D, but not T2D.
\end{abstract}

Keywords Atypical femoral fractures $\cdot$ Diabetes type $1 \cdot$ Diabetes type $2 \cdot$ Femoral shaft fracture $\cdot$ Fractures $\cdot$ Subtrochanteric fracture

N.H. Rasmussen

nicklas.rasmussen@rn.dk

1 Steno Diabetes Center North, Aalborg University Hospital, Aalborg, Denmark

2 Department of Endocrinology, Aalborg University Hospital, Aalborg, Denmark

3 Department of Clinical Pharmacy \& Toxicology, Maastricht UMC+, Maastricht, The Netherlands

4 Utrecht Institute for Pharmaceutical Sciences, Utrecht University, Utrecht, The Netherlands

5 Department of Internal Medicine, VieCuri Medical Center, Venlo, The Netherlands

6 Department of Internal Medicine, Maastricht UMC+, Maastricht, The Netherlands

7 Faculty of Medicine and Life Sciences, University Hasselt, Hasselt, Belgium

\section{Introduction}

Patients with type 1 diabetes (T1D) and type 2 diabetes (T2D) are associated with an increased risk of falls and fragility fractures compared with the general population $[15,31,34,38]$. In a recent meta-analysis, patients with T1D had a 3.16-fold increase in the risk of any fracture (95\% confidence interval (CI) 1.51-6.63), whereas the fracture risk only increased by $19 \%$ in patients with T2D (1.19 (95\% CI 1.11-1.27)) [38, 44]. In an effort to prevent fractures, antiresorptive medication has commonly been administrated, e.g., bisphosphonates (BP) and denosumab. This treatment has significantly reduced the number of fractures by increasing the bone mineral density (BMD) and improving bone microstructure [18]. However, the longterm use of this medication has been associated with a higher incidence of atypical femoral fractures (AFFs) [2, 5, 43]. In general, AFFs are rare, but important to identify, because they 
are associated with a prolonged bone healing, increased risk of complications, and long-term treatment regimens [1, 23, 24, 27]. AFFs have distinctive characteristics that distinguish them from more commonly encountered femoral fractures. The American Society for Bone and Mineral Research (ASBMR) task force has defined AFFs by their anatomical localization in the femur, the trauma mechanism, and the radiographic features [40]. To satisfy the definition of AFFs, the fracture must be located along-side the femoral diaphysis from just distal to the lesser trochanter to just proximal to the supracondylar flare. The radiographic features and the trauma mechanism distinguish AFFs from ordinary osteoporotic femoral fractures [22]. According to the ASBMR task force, several risk factors such as BPs, glucocorticoids, diabetes, and older age increase the risk of AFFs. Both diabetes and BPs have been associated with inducing a low bone turnover which increases the risk of multiple micro-fractures with the potential of leading to complete fractures over time [2, 5, 43]. A recent meta-analysis concluded that low bone turnover appears to be a common finding in diabetes [14]. AFFs also occur in the absence of BPs and other antiresorptive agents, suggesting that the low bone turnover, like that observed in patients with T1D and T2D, could be an independent risk factor for AFFs. However, contradictive studies on diabetes and AFFs exist, and few cohort studies of patients with diabetes have been investigated.

Establishing the effect of specific risk factors of AFFs is challenging due to the low incidence and the diagnostic criteria from the ASBMR. However, gaining knowledge of the potential risk and identifying specific risk factors of AFFs could guide the choice of medication or initiate a closer monitoring of people at higher risk of AFFs. Therefore, the primary aim of this study was to approximate the risk of AFFs by measuring the proportion of subtrochanteric and femoral shaft (ST/FS) fractures in patients with diabetes compared with a matched control group. A secondary aim was to identify risk factors of ST/FS fractures among patients with diabetes.

\section{Methods}

\section{Source of data}

Since 1968, the Danish Civil Registry System has assigned a unique 10-digit civil registry number (the CPR number) to all Danish residents at birth or immigration. In all Danish registries, patients are identified by their CPR number [11]. This enabled us to link national data on hospital diagnoses from the Danish National Patient Registry (DNPR) to the prescribed medication from the register of Medicinal Products Statistics of the Danish Medicines Agency to identify all patients with diabetes residing in Denmark. The DNPR tracks every hospital admission in Denmark since 1977, recording dates of admission and discharge. The registry covers $99.4 \%$ of all discharge records from Danish hospitals. It covers all inpatient contacts, outpatient visits to the hospital, and outpatient visits to clinics and emergency rooms [3]. Physicians use the Danish version of the International Classification of Diseases 8 th revision (ICD-8) (1977-1993) and 10th revision (ICD-10) (1994 onward) as part of the National Health Service Classification System (SKS) to code diagnoses. SKS keeps track of diagnoses, symptoms, health problems, and other causes of patient-associated contacts with the health services. Medications were extracted from the Medicinal Products Statistics of the Danish Medicines Agency, which is a nationwide register on all prescription drugs sold in Danish pharmacies after the year of 1996 using the Anatomical Therapeutically Chemical (ATC) classification system [46]. In Denmark, diagnostics and care of T2D is handled by GPs, whereas endocrinologists see patients with T1D and poorly regulated $\mathrm{T} 2 \mathrm{D}$ regularly.

\section{The study cohort}

This investigation was carried out using a retrospective cohort design of diabetics older than 18 years of age between the first of January 1996 until the 31st of December 2017 and their age- and sex-matched controls. Figure 1 shows the design and flow of inclusion. The cohort was divided into three groups: patients with T1D, patients with T2D, and age- and sexmatched control subjects representing the general population. Patients with T1D and T2D were identified via the ICD-10 codes and SKS system by their discharge diagnosis and by the ATC classification system. T1D $(n=19,896)$ was defined as the occurrence of at least one ICD-10 diagnosis code for T1D (ICD-10 code DE10) and at least one ATC code for insulins and analogs (ATC code A10A) and no ATC code for blood glucose-lowering drugs, excl. insulins (ATC code A10B). T2D ( $n=312,188)$ was defined as subjects with at least one ATC code A10B and no ICD-10 code DE10. The controls $(n=$ 996,252) were defined as non-diabetics from the general population matched by age and sex (3:1) with the total population of patients with diabetes. Subgroup analyses were made for patients with type 1 and type 2 diabetes and matched by age and sex (1:1) with a separate control group (Table 2).

\section{Endpoint and exposure}

The primary endpoint was ICD-10-coded ST/FS fractures in patients with diabetes compared with age- and sex-matched controls. ST fractures (ICD-10 code DS72.2) and FS fractures (ICD-10 code DS72.3) were identified in all the three groups. A secondary endpoint was to identify risk factors of ST/FS fractures among patients with diabetes. Exposure was time to event of an ST/FS fracture from the diabetes diagnosis or a 


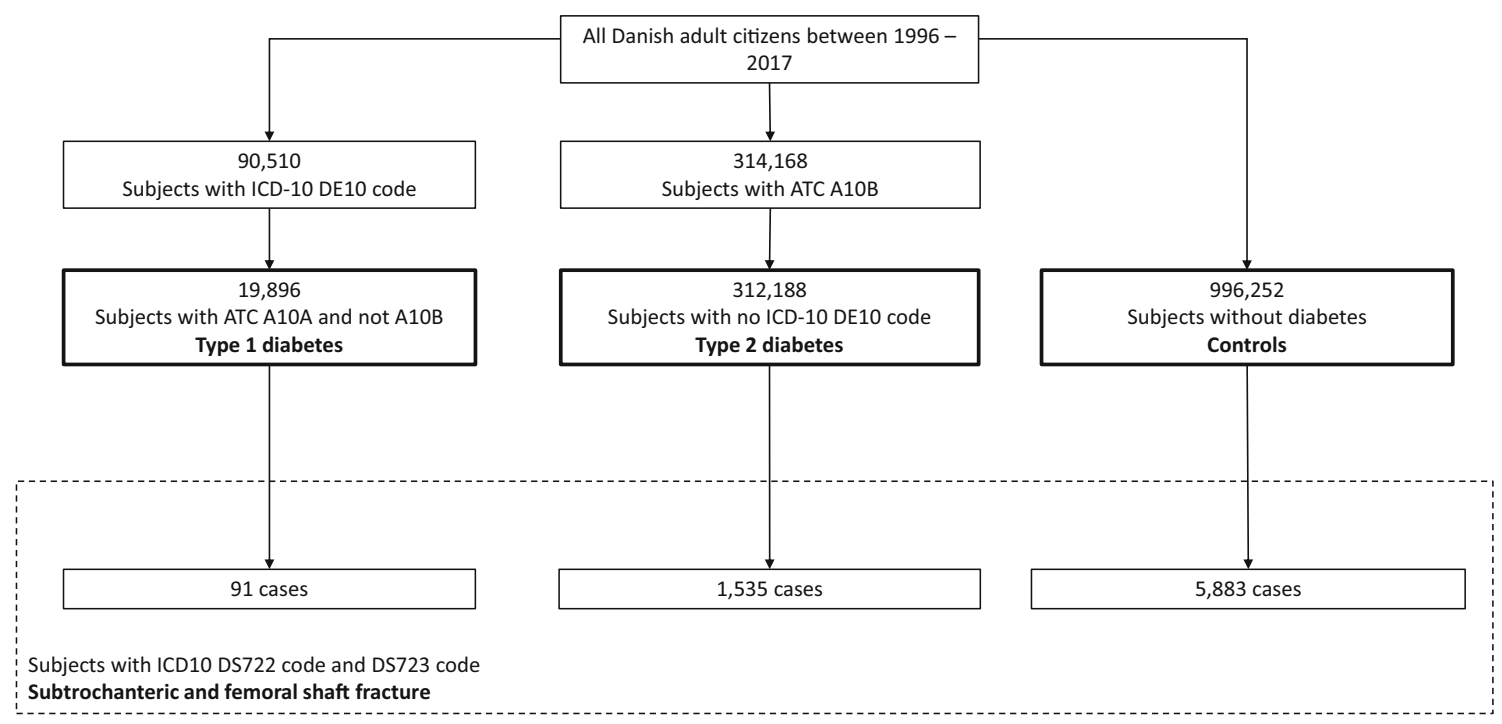

Fig. 1 Number of people in the study. From the Danish National Patient Register (DNPR), 19,896 people were identified having type 1 diabetes and 312,188 people type 2 diabetes. These were matched with 996,252 controls from the general population without diabetes by age and sex (3:1). All cases of subtrochanteric and femoral shaft fractures were identified in each group. Classification of Diseases 10 (ICD-10) system

corresponding dummy date for the age- and sex-matched controls.

\section{Statistical analyses}

Descriptive statistics were presented with a mean and standard deviation (SD) or percentage of people. $t$ tests, chi-square tests, and Mann-Whitney $U$ tests were used to present statistical differences in person characteristics. In a subgroup analysis matched by age and sex, the incidence rate (IR) and the incidence rate ratio (IRR) of ST/FS fractures were estimated from the time of diagnosis or of a corresponding dummy date for controls to the first event of ST/FS fracture for T1D or T2D patients. To exclude the same event twice, a dicatom variable was created by measuring the proportion of ST/FS fractures before and after the diagnosis. A Cox regression model was constructed to analyze the association of T1D and T2D with ST/FS fractures (Table 3). Covariates in the model included age, sex, previous ST/FS fractures, previous alcohol abuse including problems with alcohol use (ICD-10 code DF10) and psychiatric disorder and behavioral disorder from alcohol use (SKS code DZ721), previous knee and hip arthroplasties (SKS codes KNGG and KNFG), previous osteoporosis and fractures related to osteoporosis (ICD-10 codes M80-M82), and previous use of per oral and systemic glucocorticoids (ATC code $\mathrm{H} 02 \mathrm{AB}$ ) and bisphosphonates (ATC code M05BA). The analyses were conducted in SAS 9.4. The significance level was set at a $p$ value of less than 0.05 for twosided testing. and the Anatomical Therapeutical Chemical (ATC) classification system: femoral shaft fractures (ICD-10 code DS72.3), subtrochanteric fractures (ICD-10 code DS72.2), type 1 diabetes (ICD-10 code DE10). ATC code for insulins and analogs (ATC code A10A). ATC code for blood glucoselowering drugs, excl. insulins (ATC code A10B)

\section{Results}

Table 1 shows the person characteristics of patients with T1D $(n=19,896), \mathrm{T} 2 \mathrm{D}(n=312,188)$, and controls $(n=996,252)$ at the time of diagnosis. The mean age was lower in patients with T1D (36 years) compared with that in T2D patients (60 years). A higher proportion of men than women was seen in each group: T1D (60.1\%), T2D (52.5\%), and controls (52.9\%). Previous use of BPs and glucocorticoids was higher in patients with T2D (2.0\% and $22.2 \%$, respectively) compared with T1D (1.1\% and $11.9 \%$, respectively). Also, a previous diagnosis of osteoporosis was more frequent in T2D (2.3\%) than in T1D (1.4\%). On the contrary, patients with T1D (4.4\%) showed a higher proportion of previous diagnoses of alcohol abuse than T2D (2.2\%).

Table 2 is an adjusted subgroup analysis showing the IR of ST/FS fractures in T1D and matched controls and T2D and matched controls. This showed an IR of 52.14 events per 100,000 person years for an ST/FS fracture in T1D patients compared with 37.7 events for the control group, which yielded an $\mathrm{IR}_{\mathrm{T} 1 \mathrm{D}} / \mathrm{IR}_{\text {Control }}$ of 1.38. Patients with $\mathrm{T} 2 \mathrm{D}$ showed an IR of 73.21 events and similar values were shown for the control group (IR of 81.0 events) yielding an $\mathrm{IR}_{\mathrm{T} 2 \mathrm{D}} / \mathrm{IR}_{\mathrm{Control}}$ of 0.90 .

Table 3 and Fig. 2 show the results from the Cox regression analysis and the incidence plots, respectively. T1D was associated with a higher risk of ST/FS fractures (HR of 2.07 (95\% CI 1.68-2.56)) whereas T2D was not (HR 0.99 (95\% CI 0.94 1.10)). Women were more likely to have ST/FS fractures (HR 1.48 (95\% CI 1.41-1.55)) as compared with men. A previous $\mathrm{ST} / \mathrm{FS}$ fracture was associated with a higher risk of an 
Table 1 Person characteristics of patients with type 1 diabetes, type 2 diabetes, and controls

\begin{tabular}{|c|c|c|c|c|}
\hline Variable exposure & T1D & $\mathrm{T} 2 \mathrm{D}$ & Controls & $p$ \\
\hline Number of people & 19,896 & 312,188 & 996,252 & \\
\hline Age (SD) & $36(24)$ & $60(16)$ & $59(17)$ & - \\
\hline \multicolumn{5}{|l|}{ Age interval } \\
\hline$<30$ years & $9440(47.4)$ & $15,235(4.9)$ & $74,025(7.4)$ & - \\
\hline $30-40$ years & $2197(11.0)$ & $20,131(6.4)$ & $66,984(6.7)$ & - \\
\hline $40-50$ years & $2006(10.1)$ & $35,246(11.3)$ & $111,756(11.2)$ & - \\
\hline $50-60$ years & $2047(10.3)$ & $67,721(21.7)$ & $209,304(21.0)$ & - \\
\hline $60-70$ years & $1923(9.7)$ & $82,545(26.4)$ & $253,404(25.4)$ & - \\
\hline $70-80$ years & $1506(7.6)$ & $61,680(19.8)$ & $189,558(19.0)$ & - \\
\hline $80-90$ years & $689(3.5)$ & $26,036(8.3)$ & $80,175(8.0)$ & - \\
\hline$>90$ years & $88(0.4)$ & $3594(1.2)$ & $11,046(1.1)$ & - \\
\hline \multicolumn{5}{|l|}{ Sex } \\
\hline Women (\%) & 7943 (39.9) & $148,381(47.5)$ & $468,972(47.1)$ & - \\
\hline Men $(\%)$ & $11,953(60.1)$ & $163,807(52.5)$ & $527,280(52.9)$ & - \\
\hline \multicolumn{5}{|l|}{ Fractures } \\
\hline ST of femur (\%) & $57(62.6)$ & $920(59.9)$ & $3585(60.9)$ & 0.000 \\
\hline SF of femur $(\%)$ & $34(37.4)$ & $615(40.1)$ & $2298(39.1)$ & 0.000 \\
\hline $\mathrm{ST} / \mathrm{FS}$ fractures $(\%)$ & $91(0.46)$ & $1535(0.49)$ & $5883(0.59)$ & 0.000 \\
\hline Previous ST/FS fracture $(\%)$ & $57(0.3)$ & $774(0.2)$ & $2507(0.3)$ & 0.889 \\
\hline Previous arthroplasties* $(\%)$ & $5(0.0)$ & $49(0.0)$ & $125(0.0)$ & 0.110 \\
\hline \multicolumn{5}{|l|}{ Previous use of medicine } \\
\hline Peroral or systemic glucocorticoids (\%) & $2364(11.9)$ & $69,252(22.2)$ & $169,450(17.0)$ & 0.000 \\
\hline Bisphosphonates $(\%)$ & $219(1.1)$ & $6349(2.0)$ & $27,429(2.8)$ & 0.000 \\
\hline \multicolumn{5}{|l|}{ Others } \\
\hline Previous alcohol abuse (\%) & $840(4.2)$ & $6982(2.2)$ & $17,574(1.8)$ & 0.000 \\
\hline Previous osteoporosis $(\%)$ & $270(1.4)$ & $7105(2.3)$ & $28,962(2.9)$ & 0.000 \\
\hline
\end{tabular}

ST/FS subtrochanteric and femoral shaft fractures

* Arthroplasties in the knee or hip

additional ST/FS fracture (HR 6.95 (95\% CI 6.00-8.05)). An increased risk of ST/FS fractures was seen with advancing age, especially in the age span between 40 and 90 years of age. People with osteoporosis and fractures related to osteoporosis were more likely to suffer from an ST/FS fracture (HR 1.30 (95\% CI 1.16-1.46)). Previous use of BPs showed an increased risk of ST/FS fractures (HR 1.72 (95\% CI 1.54 1.91)), but not the previous use of glucocorticoids (HR 1.05 (95\% CI 0.99-1.12)). Previous alcohol abuse showed a significant increase in the risk of ST/FS fractures (HR $4.00(95 \%$ CI 3.51-4.55)). Finally, few events of arthroplasties were observed, and no significant increase of ST/FS fractures was seen (HR 1.83 (95\% CI 0.59-5.68)).

\section{Discussion}

In this population-based cohort study, we showed that patients with T1D have an increased risk of ST/FS fractures compared with matched controls. Age, previous ST/FS fractures, osteoporosis, BPs, and alcohol abuse were associated with an increased risk of ST/FS fractures. The IR of ST/FS fractures for T1D showed comparable values to studies on patients without diabetes treated with BPs $[10,28,30,35]$.

\section{Diabetes, bone turnover, and AFFs}

Diabetes is associated with a low bone turnover and a recent meta-analysis concluded that it appears to be a common finding in diabetes $[14,38]$. The low bone turnover in diabetes is believed to be caused by osteocyte dysfunction and increased sclerostin levels resulting in bone micro-cracks [43]. Other studies have shown an increase in mineralization and non-enzymatic collagen cross-links and have found lower total trabecular BMD values $[9,33,39]$. This histological pattern in patients with diabetes is in part similar to that reported in patients 
Table 2 Subgroup analyses. An estimate of the incidence rates per 100,000 person years and incidence rate ratios for a subtrochanteric or a femoral shaft fracture in patients with type 1 diabetes or type 2 diabetes to a matched control group by age and sex 1:1

\begin{tabular}{|c|c|c|c|c|}
\hline Group & Fracture type & IR per 100.000 person years: DM & IR per 100.000 person years: controls & $\operatorname{IRR}(95 \% \mathrm{CI})$ \\
\hline \multirow[t]{2}{*}{ T1D } & Subtrochanteric fracture & 32.66 & 21.47 & $1.52(1.02-2.27)$ \\
\hline & Femoral shaft fracture & 19.48 & 16.23 & $1.20(0.74-1.95)$ \\
\hline \multirow[t]{2}{*}{$\mathrm{T} 2 \mathrm{D}$} & Subtrochanteric fracture & 43.88 & 48.71 & $0.90(0.83-0.98)$ \\
\hline & Femoral shaft fracture & 29.33 & 32.28 & $0.91(0.82-1.01)$ \\
\hline
\end{tabular}

IRRs in italics indicate statistically significant results: $p<0.05$

on long-term treatment with BPs who sustain AFFs [4]. However, contradictive data exists on whether diabetes also affects the risk of AFFs. In population-based studies, only a few studies have shown that diabetes is associated with an increased risk of AFFs, whereas several larger studies suggest that patients with diabetes are at lower risk of AFFs [10, 12, 25, 29, 36]. A recent study showed an increased risk of low-energy ST/FS fractures in patients with diabetes after adjustment for BMD, age, and BPs (HR of 3.25 (95\% CI 1.55-6.82)) [29]. Another retrospective case-control study of patients with low-energy ST/FS fractures included radiological features and found a 2-fold higher prevalence of diabetes in AFF cases compared with femoral fracture cases [12]. Other studies have reported a lower prevalence of diabetes in AFF cases compared with the overall population $[10,25,36]$. However, given the potential relationship of diabetes to bone turnover and in the light of the results in this study, more evidence points towards an association between diabetes and AFFs. In this study, patients with T1D, but not T2D, were significantly associated with an increased ST/ FS fracture risk. The reason for this discrepancy between T1D and T2D may be that T1D is often diagnosed in a younger age leading to a more profound change in bone composition over time. Furthermore, patients with T2D are often overweight in contrast to patients with T1D, who are often of normal weight or even underweight. The extra weight in patients with T2D perhaps manifests especially around the hips as padding, possibly having a hip protecting effect. On the contrary, a study on obese women without diabetes showed no protecting effect regarding obesity and hip fractures [16]. Diabetes and bone are complex and the discrepancy in ST/FS fractures thus represents an interesting insight into bone biomechanical competence in T1D and T2D, which requires further study.

\section{Risk factors}

In this study, potential risk factors were identified and will be discussed in the following.
People with osteoporosis and people treated with BPs were independently associated with ST/FS fractures. This could indicate that ST/FS fractures or AFFs are an extreme manifestation of severe osteoporosis with decreased bone biomechanical competence or represent a distinctive entity defined as AFFs. In addition, commencement of BP treatment does not necessarily occur in patients with severe osteoporosis alone, although BPs would be indicated. Furthermore, the association between ST/FS fractures and BPs matched other study findings using similar methods. In previous studies, the longterm use of BPs has shown IRs between 3.2 and 50 events per 100,000 person years for AFFs [40]. A comparable IR was seen in this study of patients with T1D and the risk for ST/FS fractures. In addition, the corresponding IRR was lower than the adjusted Cox regression model, indicating multiple exposures, such as BPs. Due to the risk of AFFs, physicians tend to undertreat patients with diabetes with BPs for osteoporosis compared with the general population [45]. In view of the low IR, the benefits of treating osteoporosis in patients with diabetes with BPs significantly outweigh the risk of ST/FS fractures or of AFFs, and treatment should be considered similar to the general population [19].

In this study, people with a previous ST/FS fracture showed a 7-folded increase of an additional fracture. In general, previous non-accidental and low-energy non-AFFs increase the risk of an additional fracture, and the same mechanism may apply for ST/FS fractures [7, 42]. Moreover, the non-AFF fractures could also increase the risk of AFFs, but more studies are needed to explore this.

People with a previous alcohol abuse were highly associated with an increased risk of ST/FS fractures. A recent study showed a 3-folded increase of fractures in patients with diabetes associated with an alcohol-related diagnosis [42]. There are several mechanisms whereby alcohol might adversely affect the fracture risk. Over time, alcohol decreases the bone turnover due to malabsorption, malnutrition, and metabolic effects from alcohol resulting in calcium deficits, which could increase the risk of AFFs [17, 32]. Patients with diabetes, especially T1D, are often malnourished and in deficit of vital minerals and vitamins due to autonomic effects of the disease [17]. The negative effects from extensive use of alcohol could be more pronounced in patients with diabetes compared with 
Table 3 Results from the Cox regression analysis with events of subtrochanteric and femoral shaft fractures as outcome and diabetes, age, sex, fracture, medicine, alcohol, and osteoporosis as exposure

\begin{tabular}{|c|c|c|c|c|}
\hline & HR & & $95 \% \mathrm{CI}$ & $p$ \\
\hline Type & & & & $<0.0001$ \\
\hline T1D & 2.07 & & $1.68-2.56$ & \\
\hline $\mathrm{T} 2 \mathrm{D}$ & 0.99 & & $0.94-1.10$ & 0.7883 \\
\hline Controls & 1 & & - & - \\
\hline \multicolumn{5}{|l|}{ Sex } \\
\hline Women & 1.48 & & $1.41-1.55$ & $<0.0001$ \\
\hline Male & 1 & & - & - \\
\hline \multicolumn{5}{|l|}{ Age interval/years } \\
\hline$<30$ & 1 & & - & - \\
\hline $30-40$ & 1.01 & & $0.67-1.52$ & 0.9691 \\
\hline $40-50$ & 2.99 & & $2.18-4.10$ & $<0.0001$ \\
\hline $50-60$ & 4.67 & & $3.48-6.27$ & $<0.0001$ \\
\hline $60-70$ & 11.42 & & $8.56-15.22$ & $<0.0001$ \\
\hline $70-80$ & 28.97 & & $21.76-38.57$ & $<0.0001$ \\
\hline $80-90$ & 71.03 & & $53.30-94.67$ & $<0.0001$ \\
\hline$>90$ & 125.43 & & $92.23-170.54$ & $<0.0001$ \\
\hline \multicolumn{5}{|l|}{ Fractures } \\
\hline Previous fractures (yes) & 6.95 & $6.00-8.05$ & $<0.0001$ & \\
\hline Previous arthroplasties (yes) & 1.83 & $0.59-5.68$ & 0.2957 & \\
\hline \multicolumn{5}{|l|}{ Previous use of medicine } \\
\hline Systemic or peroral glucocorticoids (yes) & & 1.05 & $0.99-1.12$ & 0.0806 \\
\hline Bisphosphonates (yes) & & 1.72 & $1.54-1.91$ & $<0.0001$ \\
\hline \multicolumn{5}{|l|}{ Others (previous) } \\
\hline Alcohol abuse (yes) & & 4.00 & $3.51-4.55$ & $<0.0001$ \\
\hline Osteoporosis (yes) & & 1.30 & $1.16-1.46$ & $<0.0001$ \\
\hline
\end{tabular}

The model was adjusted for diabetes, age, sex, previous subtrochanteric and femoral shaft fractures, previous arthroplasties in the knee or hip, previous systemic or peroral glucocorticoids, previous bisphosphonates, previous alcohol abuse, and previous osteoporosis. Hazard ratios (HR) in italics indicate statistically significant results. $C I$, confidence interval

patients without diabetes. Therefore, alcohol should be considered a severe risk factor of ST/FS fractures among other diseases.

Both increasing age and women were associated with ST/ FS fractures. In general, women have an increased risk of fractures, including ST/FS fractures and AFFs, probably due to the lack of estrogen following menopause $[8,13,36]$. On average, patients who develop AFFs or ST/FS fractures are younger (2-6 years) than those who develop non-AFFs [36]. Similar to femoral fractures, the risk of AFFs increases with age, and BPs delay the risk of femoral fractures, but accelerate the occurrence of AFFs.

Glucocorticoids are known to reduce bone turnover which increases the risk of osteoporosis and fractures, but in this study, they did not increase the risk of ST/FS fractures []. Yet other studies have suggested a positive correlation between glucocorticoids and AFFs [6]. The variety of durations, doses, and conditions for which glucocorticoids are used has complicated the assessment of the relationship to AFFs. It is probable that those on higher doses of glucocorticoids may also be more likely to be using BPs. However, in this study design, both exposures were excluded in the adjusted analysis.

\section{Strengths}

This study has a number of advantages for addressing the association of diabetes to ST/FS fractures. It is a cohort study which allows for population-based estimates of incidences, risk assessments, and characterization of ST/FS fractures in patients with diabetes. In addition, the control group represents the general population, which gives the opportunity to estimate the absolute number of ST/FS fractures in the population compared to, e.g., case-control studies which tend to use a fracture control group. Furthermore, comprehensive adjustments eliminated the confounding risk factors associated with ST/FS fractures as previous fractures, arthroplasties, osteoporosis, BPs, alcohol abuse, glucocorticoids, age, and sex. Especially hip and knee arthroplasties did not increase the risk 


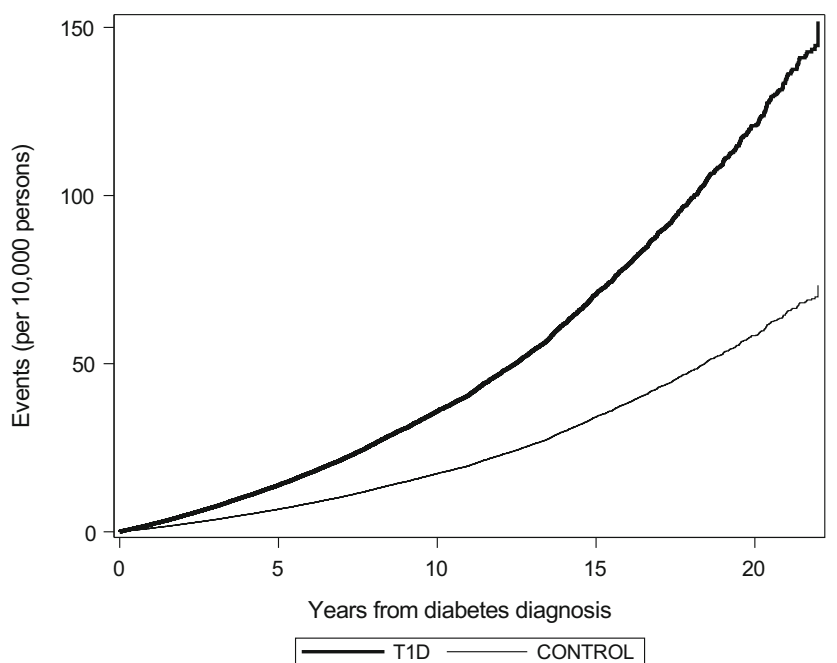

Fig. 2 Incidents plot of hazard ratios from the Cox regression. Years from diabetes diagnosis or a dummy date for controls to first incidence of subtrochanteric and femoral shaft fracture. The model was adjusted for age, sex, previous subtrochanteric and femoral shaft fractures, previous

of ST/FS fractures, but have been associated with an increased risk of periprosthetic ST/FS fractures among BP users, which in some studies account for $15 \%$ of the cases [22].

ICD-10 codes were used to identify ST/FS fractures. In most studies restricted to ICD codes of ST/FS fractures, the majority (75-95\%) did not meet the ASBMR criteria and would not qualify as AFFs [36]. Upon radiographic review, most ST/FS fractures were, e.g., periprosthetic, pathologic fractures, miscoded intertrochanteric fractures, osteoporotic fractures, or ST/FS fractures that were not AFFs [20]. However, the validity of registrations in the DNPR is in general very high, and especially the surgical diagnosis codes as ST/FS and arthroplasties (95\% validation or higher) [26, 37, 41]. Therefore, a proportion of the ST/FS fractures could be considered AFFs. Moreover, analyzing the total number of ST/FS fractures allows for inferences about the potential net harm and provide an estimate of the upper boundary of harm of all fractures located in this part of the femur in patients with diabetes. An optimal setting could include the ASBMR criteria, but access to medical journals or radiographic features was not possible. The ASBMR criteria are considered to be of high value in identifying AFFs. However, a recent study found discrepancies between ASBMR criteria-based and expert-based determinations on how to classify specific radiological features in almost one-third of the cases [21]. The ASBMR criteria are useful, but several features could be difficult to interpret when applying the radiological features.

\section{Limitations}

In this study, people with T1D have an increased risk of ST/FS fractures compared with controls. However, some limitations have to be considered. First, additional adjustment for other

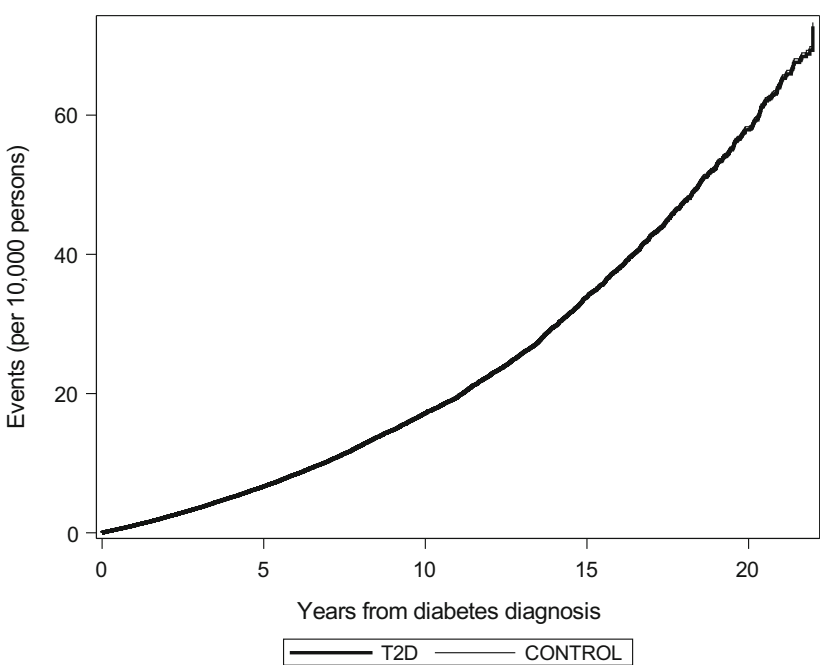

arthroplasties in the knee or hip, previous use of systemic or peroral glucocorticoids, previous bisphosphonates, previous alcohol abuse, and previous osteoporosis. T1D compared to controls showed a p-value $<0.0001$ and T2D compared to controls showed a p-value of 0.7883

antiresorptives and body mass index (BMI) was not added to the analyses, due to the limited cases of ST/FS fractures and the restricted access to patient records. Denosumab was introduced in 2011 and the registered effect so far on AFFs is limited. Regarding BMI and AFFs, limited data exits. However, two studies showed no connection between BMI and ST/FS fractures or verified radiological AFFs, whereas another small study found that AFF patients had a higher BMI than controls [, 10]. Second, approximately 70,000 people were excluded in the study design when adding at least one ATC code for insulins and analogs (ATC A10A) and no ATC code for blood glucose-lowering drugs, excl. insulins (ATC code A10B). However, the majority of this cohort are most likely patients with T2D with a hospital diagnosis at the time of admission. Therefore, these subjects could not have influenced the T1D cohort. Third, ICD-10 codes were used to identify ST/FS fractures as a proportion of AFFs. According to newer guidelines, the ASBMR criteria should be applied. However, identifying an increased risk of ST/FS fractures thus represents an interesting insight into the complex mechanism of bone biomechanicals and open up the possibility that the risk of AFFs also could be increased, which requires further study.

\section{Conclusion}

In conclusion, this study showed an increased risk of ST/FS fractures in patients with T1D. Analyses of ST/FS fractures in patients with diabetes provide valuable information about the potential net harm and upper boundary of harm of all fractures located in the ST/FS region. Moreover, using a cohort study design allowed for extensive adjustments, not seen in similar 
studies, to eliminate confounding associated with ST/FS fractures. Diabetes is associated with a low bone turnover which is similar to that reported in patients on long-term treatment with BPs who sustain AFFs. Hence, a similar etiology could exists between diabetes and the development of AFFs. Furthermore, a proportion of ST/FS fractures are AFFs. Therefore, the risk of ST/FS fractures in this study could represent the risk of AFFs in patients with T1D. In addition, several risk factors were associated with ST/FS fractures and may represent risk factors of AFFs. In an optimal setting, the ASBMR criteria for AFFs could be added to reinforce the diagnosis.

AFFs are an extremely rare manifestation, but yet important to be identified in order to reduce the severe consequences associated with these fractures. Knowledge of the association between diabetes, ST/FS fractures, AFFs, and potential risk factors could prompt the physicians to initiate a closer clinical monitoring of people at high risk with several risk factors to prevent new cases of AFFs. Especially patients with diabetes who have an increased risk of fragility fractures and falls could benefit from this by reducing morbidity and increasing their quality of life.

\section{Compliance with ethical standards}

Conflicts of interest None.

\section{References}

1. Adler RA (2016) Bisphosphonates and atypical femoral fractures. Curr Opin Endocrinol Diabetes Obes 23:430-434

2. Adler RA (2018) Management of endocrine disease: Atypical femoral fractures: risks and benefits of long-term treatment of osteoporosis with anti-resorptive therapy. Eur J Endocrinol 178:R81-R87

3. Andersen TF, Madsen M, Jørgensen J, Mellemkjoer L, Olsen JH (1999) The Danish National Hospital Register. A valuable source of data for modern health sciences. Dan Med Bull 46:263-268

4. Armamento-Villareal R, Napoli N, Panwar V, Novack D (2006) Suppressed bone turnover during alendronate therapy for highturnover osteoporosis. N Engl J Med 355:2048-2050

5. Aspenberg P (2014) Denosumab and atypical femoral fractures. Acta Orthop 85:1-1

6. Black DM, Kelly MP, Genant HK, Palermo L, Eastell R, BucciRechtweg C, Cauley J, Leung PC, Boonen S, Santora A, de Papp A, Bauer DC, Fracture Intervention Trial Steering Committee, HORIZON Pivotal Fracture Trial Steering Committee (2010) Bisphosphonates and fractures of the subtrochanteric or diaphyseal femur. N Engl J Med 362:1761-1771

7. Center JR, Bliuc D, Nguyen TV, Eisman JA (2007) Risk of subsequent fracture after low-trauma fracture in men and women. $\mathrm{J}$ Am Med Assoc 297:387-394

8. Ensrud KE (2013) Epidemiology of fracture risk with advancing age. Journals Gerontol Ser A Biol Sci Med Sci 68:1236-1242

9. Farlay D, Armas LA, Gineyts E, Akhter MP, Recker RR, Boivin G (2016) Nonenzymatic glycation and degree of mineralization are higher in bone from fractured patients with type 1 diabetes mellitus. J Bone Miner Res 31:190-195
10. Feldstein AC, Black D, Perrin N et al (2012) Incidence and demography of femur fractures with and without atypical features. J Bone Miner Res 27:977-986

11. Frank L (2000) Epidemiology. When an entire country is a cohort. Science 287:2398-2399

12. Giusti A, Hamdy NAT, Dekkers OM, Ramautar SR, Dijkstra S, Papapoulos SE (2011) Atypical fractures and bisphosphonate therapy: a cohort study of patients with femoral fracture with radiographic adjudication of fracture site and features. Bone 48:966-971

13. Hopkins RB, Pullenayegum E, Goeree R, Adachi JD, Papaioannou A, Leslie WD, Tarride JE, Thabane L (2012) Estimation of the lifetime risk of hip fracture for women and men in Canada. Osteoporos Int 23:921-927

14. Hygum K, Starup-Linde J, Harsløf T, Vestergaard P, Langdahl BL (2017) Mechanisms in endocrinology: Diabetes mellitus, a state of low bone turnover - a systematic review and meta-analysis. Eur J Endocrinol 176:R137-R157

15. Janghorbani M, Van Dam RM, Willett WC, Hu FB (2007) Systematic review of type 1 and type 2 diabetes mellitus and risk of fracture. Am J Epidemiol 166:495-505

16. Johansson H, Kanis JA, Odén A, McCloskey E, Chapurlat RD, Christiansen C, Cummings SR, Diez-Perez A, Eisman JA, Fujiwara S, Glüer CC, Goltzman D, Hans D, Khaw KT, Krieg MA, Kröger H, LaCroix A, Lau E, Leslie WD, Mellström D, Melton LJ 3rd, O'Neill TW, Pasco JA, Prior JC, Reid DM, Rivadeneira F, van Staa T, Yoshimura N, Zillikens MC (2014) A meta-analysis of the association of fracture risk and body mass index in women. J Bone Miner Res 29:223-233

17. Kanis JA, Johansson H, Johnell O, Oden A, De Laet C, Eisman JA, Pols H, Tenenhouse A (2005) Alcohol intake as a risk factor for fracture. Osteoporos Int 16:737-742

18. Khosla S, Bilezikian JP, Dempster DW, Lewiecki EM, Miller PD, Neer RM, Recker RR, Shane E, Shoback D, Potts JT (2012) Benefits and risks of bisphosphonate therapy for osteoporosis. J Clin Endocrinol Metab 97:2272-2282

19. Khow KSF, Shibu P, Yu SCY, Chehade MJ, Visvanathan R (2017) Epidemiology and postoperative outcomes of atypical femoral fractures in older adults: a systematic review. J Nutr Health Aging 21:83-91

20. LeBlanc ES, Rosales AG, Black DM, Genant HK, Dell RM, Friess DM, Boardman DL, Bauer DC, de Papp A, Santora AC, Orwoll ES (2017) Evaluating atypical features of femur fractures: how change in radiological criteria influenced incidence and demography of atypical femur fractures in a community setting. J Bone Miner Res 32:2304-2314

21. LeBlanc ES, Rosales AG, Genant HK et al (2019) Radiological criteria for atypical features of femur fractures: what we can learn when applied in a clinical study setting. Osteoporos Int 30:12871295. https://doi.org/10.1007/s00198-019-04869-z

22. Leclerc J-T, Michou L, Vaillancourt F, Pelet S, Simonyan D, Belzile EL (2019) Prevalence and characteristics of atypical periprosthetic femoral fractures. J Bone Miner Res 34:83-92

23. Lee K-J, Min B-W (2018) Surgical treatment of the atypical femoral fracture: overcoming femoral bowing. Hip pelvis 30:202-209

24. Lim S-J, Yeo I, Yoon P-W, Yoo JJ, Rhyu K-H, Han S-B, Lee W-S, Song J-H, Min B-W, Park Y-S (2018) Incidence, risk factors, and fracture healing of atypical femoral fractures: a multicenter casecontrol study. Osteoporos Int 29:2427-2435

25. Lo JC, Huang SY, Lee GA, Khandewal S, Provus J, Ettinger B, Gonzalez JR, Hui RL, Grimsrud CD, Grimsrud CD (2012) Clinical correlates of atypical femoral fracture. Bone 51:181-184

26. Lynge E, Sandegaard JL, Rebolj M (2011) The Danish National Patient Register. Scand J Public Health 39:30-33

27. Medda S, Pilson H (2019) Subtrochanteric femur fractures. StatPearls Publishing 
28. Meier RPH, Perneger TV, Stern R, Rizzoli R, Peter RE (2012) Increasing occurrence of atypical femoral fractures associated with bisphosphonate use. Arch Intern Med 172:930-936

29. Napoli N, Schwartz AV, Palermo L, Jin JJ, Wustrack R, Cauley JA, Ensrud KE, Kelly M, Black DM (2013) Risk factors for subtrochanteric and diaphyseal fractures: the study of osteoporotic fractures. J Clin Endocrinol Metab 98:659-667

30. Park-Wyllie LY, Mamdani MM, Juurlink DN, Hawker GA, Gunraj N, Austin PC, Whelan DB, Weiler PJ, Laupacis A (2011) Bisphosphonate use and the risk of subtrochanteric or femoral shaft fractures in older women. JAMA 305:783

31. Rasmussen NH, Dal J (2019) Falls and fractures in diabetes - more than bone fragility. Curr Osteoporos Rep 17:147-156. https://doi. org/10.1007/s11914-019-00513-1

32. Rico: Alcohol and bone disease - Google Scholar. https://scholargoogle-com.auh.aub.aau.dk/scholar_lookup?author=. Rico\&journal=Alcohol\&volume $=25 \&$ pages $=345 \&$ publication year=1990. Accessed 1 Nov 2019

33. Samelson EJ, Demissie S, Cupples LA, Zhang X, Xu H, Liu CT, Boyd SK, McLean R, Broe KE, Kiel DP, Bouxsein ML (2018) Diabetes and deficits in cortical bone density, microarchitecture, and bone size: Framingham HR-pQCT Study. J Bone Miner Res 33:54-62

34. Sarodnik C, Bours SPG, Schaper NC et al (2018) Fracture risk in patients with type 2 diabetes mellitus and possible risk factors: a systematic review and meta-analysis. Osteoporos Int 18:427-444

35. Schilcher J, Michaëlsson K, Aspenberg P (2011) Bisphosphonate use and atypical fractures of the femoral shaft. N Engl J Med 364: $1728-1737$

36. Schilcher J, Koeppen V, Aspenberg P, Michaëlsson K (2015) Risk of atypical femoral fracture during and after bisphosphonate use. Acta Orthop 86:100-107

37. Schmidt M, Schmidt SAJ, Sandegaard JL, Ehrenstein V, Pedersen L, Sørensen HT (2015) The Danish National Patient Registry: a review of content, data quality, and research potential. Clin Epidemiol 7:449
38. Shah VN, Shah CS, Snell-Bergeon JK et al (2015) Type 1 diabetes and risk of fracture: meta-analysis and review of the literature. Diabet Med 32:1134-1142

39. Shanbhogue VV, Hansen S, Frost M, Jørgensen NR, Hermann AP, Henriksen JE, Brixen K (2015) Bone geometry, volumetric density, microarchitecture, and estimated bone strength assessed by HRpQCT in adult patients with type 1 diabetes mellitus. J Bone Miner Res 30:2188-2199

40. Shane E, Burr D, Abrahamsen B, Adler RA, Brown TD, Cheung AM, Cosman F, Curtis JR, Dell R, Dempster DW, Ebeling PR, Einhorn TA, Genant HK, Geusens P, Klaushofer K, Lane JM, McKiernan F, McKinney R, Ng A, Nieves J, O'Keefe R, Papapoulos S, Howe TS, van der Meulen M, Weinstein RS, Whyte MP (2014) Atypical subtrochanteric and diaphyseal femoral fractures: second report of a Task Force of the American Society for Bone and Mineral Research. J Bone Miner Res 29:1-23

41. Sing C-W, Woo Y-C, Lee ACH, Lam JKY, Chu JKP, Wong ICK, Cheung C-L (2017) Validity of major osteoporotic fracture diagnosis codes in the Clinical Data Analysis and Reporting System in Hong Kong. Pharmacoepidemiol Drug Saf 26:973-976

42. Starup-Linde J, Gregersen S, Vestergaard P (2016) Associations with fracture in patients with diabetes: a nested case-control study. BMJ Open. https://doi.org/10.1136/bmjopen-2015-009686

43. Starup-Linde J, Hygum K, Langdahl BL (2018) Skeletal fragility in type 2 diabetes mellitus. Endocrinol Metab 33:339

44. Vestergaard P (2007) Discrepancies in bone mineral density and fracture risk in patients with type 1 and type 2 diabetes-a metaanalysis. Osteoporos Int 18:427-444

45. Vestergaard P, Rejnmark L, Mosekilde L (2011) Are antiresorptive drugs effective against fractures in patients with diabetes? Calcif Tissue Int 88:209-214

46. Wallach Kildemoes H, Toft Sørensen H, Hallas J (2011) The Danish National Prescription Registry. Scand J Public Health 39: $38-41$

Publisher's note Springer Nature remains neutral with regard to jurisdictional claims in published maps and institutional affiliations. 